\title{
Observational failure analysis of precast buildings after the 2012 Emilia earthquakes
}

\author{
Fabio Minghini*1 ${ }^{* 1}$ Elena Ongaretto ${ }^{2 a}$, Veronica Ligabue ${ }^{2 b}$, Marco Savoia $^{2 c}$ \\ and Nerio Tullini ${ }^{1 \mathrm{~d}}$ \\ ${ }^{1}$ Engineering Department - ENDIF, University of Ferrara, Via G. Saragat 1, 44122, Ferrara, Italy \\ ${ }^{2}$ Department of Civil, Chemical, Environmental, and Materials Engineering - DICAM, University of Bologna, \\ Viale Risorgimento 2, 40136, Bologna, Italy
}

(Received October 3, 2015, Revised July 22, 2016, Accepted July 28, 2016)

\begin{abstract}
The 2012 Emilia (Italy) earthquakes struck a highly industrialized area including several thousands of industrial prefabricated buildings. Due to the lack of specific design and detailing for earthquake resistance, precast reinforced concrete (RC) buildings suffered from severe damages and even partial or total collapses in many cases. The present study reports a data inventory of damages from field survey on prefabricated buildings. The damage database concerns more than 1400 buildings (about $30 \%$ of the total precast building stock in the struck region). Making use of the available shakemaps of the two mainshocks, damage distributions were related with distance from the nearest epicentre and corresponding Pseudo-Spectral Acceleration for a period of 1 second (PSA at $1 \mathrm{~s}$ ) or Peak Ground Acceleration (PGA). It was found that about $90 \%$ of the severely damaged to collapsed buildings included into the database stay within $16 \mathrm{~km}$ from the epicentre and experienced a PSA larger than $0.12 \mathrm{~g}$. Moreover, $90 \%$ of slightly to moderately damaged buildings are located at less than $25 \mathrm{~km}$ from the epicentre and were affected by a PSA larger than $0.06 \mathrm{~g}$. Nevertheless, the undamaged buildings examined are almost uniformly distributed over the struck region and $10 \%$ of them suffered a PSA not lower than $0.19 \mathrm{~g}$. The damage distributions in terms of the maximum experienced PGA show a sudden increase for PGA $\geq 0.28 \mathrm{~g}$. In this PGA interval, 442 buildings were collected in the database; $55 \%$ of them suffered severe damages up to collapse, $32 \%$ reported slight to moderate damages, whereas the remaining $13 \%$ resulted undamaged.
\end{abstract}

Keywords: precast RC buildings; damages; Emilia earthquake; seismic retrofitting; peak ground acceleration; pseudo-spectral acceleration

\section{Introduction}

Since Spitak (Armenia) earthquake in 1988, precast industrial buildings lacking of a suitable

*Corresponding author, Ph.D., E-mail: fabio.minghini@unife.it

${ }^{a} \mathrm{Ph} . D$. Student, E-mail: elena.ongaretto@unibo.it

${ }^{b}$ Ph.D. Student, E-mail: veronica.ligabue2@unibo.it

${ }^{c}$ Professor, E-mail: marco.savoia@unibo.it

dAssociate Professor, E-mail: nerio.tullini@unife.it 
seismic design have showed a unique behaviour, generally characterized by extended collapses of girders and roof elements (Yanev 1989). During that earthquake, multi-storey precast frame-panel buildings showed poor performances, especially due to the low ductility of the connections (Hadjian 1988). Heavy damages strictly related to deficiencies of connections between precast members and inadequate flexural reinforcement in precast RC columns were also documented after the 1999 Kocaeli (Turkey) earthquake (Saatcioglu et al. 2001). The results obtained from several non-linear time history analyses of typical Turkish single-storey precast industrial buildings indicated that flexural damages at the base of the columns should mainly be ascribed to near-fault earthquakes (Yüksel and Sürmeli 2010). Sezen and Whittaker (2006) categorized observational damage data from Kocaeli earthquake according to a performance scale composed by five and four levels of structural and non-structural damages, respectively. The effects of infill walls on the seismic response of precast industrial buildings in Turkey was highlighted by Korkmaz and Karahan (2011), who performed a series of non-linear analyses. In the presence of masonry curtain walls, the stability and integrity of the precast structures resulted often to be enhanced, even if the stiffening effects of the walls may lead to an increase of the earthquake actions. With regard to another, more recent destructive earthquake occurred in Turkey, i.e., the 2011 Van earthquake, the effects of improper design and detailing of connections in precast concrete structures under construction were reported by Ozden et al. (2014). The strong vulnerability of totally or partially precast structures not designed for the earthquake resistance was also highlighted after the 2008 Sichuan (China) earthquake. In particular, many schools built using a hybrid structural system with unreinforced masonry walls, cast-in-place concrete beams, and precast concrete floor elements suffered from a disproportionate number of collapses (Miyamoto et al. 2008, China Earthquake Field Investigation Report 2008). During the 2010 Haiti earthquake and 2011 sequence of events around Christchurch (New Zealand), considerable damages occurred in numerous low-rise industrial buildings (Marshall and Gould 2012). In particular, many modern industrial structures, based on the use of load-bearing concrete panels, or steel frames with concrete or unreinforced masonry cladding, suffered significant structural and non-structural damages.

In Italy, the high vulnerability of precast concrete cladding panels in industrial buildings was evidenced, probably for the first time, after the 2009 L'Aquila earthquake, that revealed the inadequacy of typical steel connections between panels and main structural elements (Toniolo and Colombo 2012). Recently, numerical models were developed to study the role of the wall panel connections for different degrees of interaction with the precast structure (Biondini et al. 2013).

The 2012 earthquake sequence in Northern Italy (Emilia earthquake) is considered the most severe seismic event in terms of damages and collapses suffered by precast RC industrial buildings. The region struck by the earthquake mainshocks is one of the most productive areas in Italy, and is characterized by medium-to-small clusters of industrial buildings located in the various municipalities. In the Emilia region, most of precast RC buildings have a single-storey structure, typically composed of a series of basic portal frames. Each frame is constituted by columns clamped in cast-in-place or precast pocket foundations, main girders simply-supported on corbels at the top of the columns and precast slab elements also simply-supported in correspondence of the main girders. Some buildings may have two floors, and others an intermediate floor in a portion of the building, typically along one of the two short edges, where offices are located. Because the region was not covered by seismic code requirements until October 2005, the beam-column and slab-beam supports are typically friction-based, without any mechanical connection device. 
For the industrial buildings struck by the 2012 Emilia earthquakes, Savoia et al. (2012) identified two main categories of precast RC structures: $i$ ) buildings constructed from 1970 to 1990 (Type 1), with beam span length from 12 to $20 \mathrm{~m}$, roof slab span length from 6 to $10 \mathrm{~m}$, and masonry infills; ii) more recent buildings (Type 2), approximately built after 1990, featuring significantly longer spans of beams and roofing elements, and either horizontal or vertical prefabricated RC cladding panels. These two building types approximately correspond to those identified by Casotto et al. (2015). Analyses of the damages reported by the industrial buildings in Emilia were presented by Savoia et al. (2012), Liberatore et al. (2013), Bournas et al. (2014) and Belleri et al. (2015).

In the present paper, the preliminary results obtained from field survey data on damages in precast RC industrial buildings hit by the 2012 Emilia earthquakes are presented. The paper describes the damage data collection process, and provides for the first time damage distributions in the area as a function of epicentral distance or of Pseudo-Spectral Acceleration for a period of 1 second (PSA at $1 \mathrm{~s}$ ).

In the largest part of the territory, the maximum seismic intensity was recorded during the May $20^{\text {th }}$ or $29^{\text {th }}, 2012$, earthquakes (Braga et al. 2014). Therefore, epicentral distances and PSA were referred to these two events. A total of 1421 buildings were included in the study, corresponding to approximately $30 \%$ of the industrial buildings in the struck area. Depending on the damage entity, the buildings were classified into six damage levels, from no damage up to collapse, according to the European Macroseismic Scale EMS-98 (1998).

\section{The 2012 Emilia earthquakes}

The earthquakes that struck the Northern Italy in May 2012 can be collected in two main sequences, with the mainshocks of comparable energy. They occurred on May $20^{\text {th }}$ and $29^{\text {th }}$, with epicentral coordinates and local magnitude N44.889, E11.228, $\mathrm{M}_{\mathrm{L}}=5.9$ and N44.851, E11.086, $\mathrm{M}_{\mathrm{L}}=5.8$, respectively (Dolce and Di Bucci 2014). The first mainshock (May 20 ${ }^{\text {th }}$ ) was recorded also from the station of San Nicandro Garganico, located in Southern Italy, at a distance from the epicentre of about $500 \mathrm{~km}$. The horizontal (subscript "h") and vertical (subscript "v") Peak Ground Accelerations (PGA) recorded on May $20^{\text {th }}$ at Mirandola (epicentral distance $R_{\text {epi }}=12.3 \mathrm{~km}$ ), the only fixed station initially located in the epicentral area, were $P G A_{h}=2.60 \mathrm{~m} / \mathrm{s}^{2}$ and $P G A_{v}=3.00$ $\mathrm{m} / \mathrm{s}^{2}$. Peak Ground Velocities (PGV) were $P G V_{h}=0.47 \mathrm{~m} / \mathrm{s}$ and $P V_{v}=0.06 \mathrm{~m} / \mathrm{s}(I N G V ~ 2012)$. After the first mainshock, 10 additional real-time stations were positioned within few tens of kilometres from the epicentre by the Italian National Institute of Geophysics and Vulcanology (INGV), and 11 additional temporary stations were installed in the epicentral area by the Italian Department of Civil Protection (DPC), see the paper by Cultrera et al. (2014). Therefore, the second mainshock (May 29 ${ }^{\text {th }}$ ) was much better monitored than the first event. In this case, the strong motion data obtained from the station of Mirandola, once again the closest to the epicentre (epicentral distance $R_{\text {epi }}=4.1 \mathrm{~km}$ ), were $P G A_{h}=2.90 \mathrm{~m} / \mathrm{s}^{2}$ and $P G V_{\mathrm{h}}=0.57 \mathrm{~m} / \mathrm{s}$ for the strongest horizontal component, and $\mathrm{PGA}_{\mathrm{v}}=9.00 \mathrm{~m} / \mathrm{s}^{2}$ and $\mathrm{PGV}_{\mathrm{v}}=0.28 \mathrm{~m} / \mathrm{s}$ for the vertical component (INGV 2012). Note the very high value of $P_{G A}$, typical of near-fault earthquakes.

The region struck by the earthquake was not covered by seismic design regulations until October 2005. Therefore, most of the buildings were lacking of proper design and detailing for earthquake resistance. This circumstance undoubtedly represented the main cause of collapses in precast RC industrial buildings (Savoia et al. 2012). In addition, acceleration and displacement 
response spectra of the two mainshocks exhibited significant amplifications in the medium-to-long period range typical of precast RC structures ( $1 \mathrm{~s}-3 \mathrm{~s}$ ), due to the peculiar soil characteristics of the Po River Plain, with the presence of very deep alluvial deposits (Dolce and Di Bucci 2014).

\subsection{The area subjected to post-earthquake field survey}

The May $20^{\text {th }}$ mainshock caused the collapse of several precast RC buildings in the industrial areas of S. Agostino, Bondeno, Finale Emilia and S. Felice sul Panaro, whereas the May $29^{\text {th }}$ earthquake was particularly severe for industrial buildings in Mirandola, Cavezzo and Medolla (see Fig. 1 reported by Liberatore et al. 2013). The first post-earthquake surveys indicated that, in some industrial areas, almost $70 \%$ of precast RC buildings collapsed or were severely damaged (Savoia et al. 2012). On $90 \%$ of the territory, the maximum seismic intensity was recorded during the May $20^{\text {th }}$ or $29^{\text {th }}, 2012$, earthquakes. All other subsequent shocks were significant for the remaining $10 \%$ of the struck area (see Fig. 4 reported by Braga et al. 2014). Five of these shocks occurred with local magnitude $\mathrm{M}_{\mathrm{L}}>5.0$, on an E-W oriented area wider than $50 \mathrm{~km}$ (Dolce and Di Bucci 2014).

After the earthquake sequence, the assessment of the seismic vulnerability became mandatory before restarting working activities for the industrial buildings located in 52 municipalities in an area extended up to $10 \mathrm{~km}$ from the epicentres of shocks with $\mathrm{M}_{\mathrm{L}} \geq 3.5$ (Legislative Decree No. 74/2012, Dolce and Di Bucci 2014).

In the present study, damage surveys on over 1400 industrial buildings are collected and analyzed. All industrial buildings considered in the database are located in municipalities of Emilia-Romagna region lying in the area where assessment of seismic vulnerability was mandatory, with a distance from the closest epicentre lower than $37 \mathrm{~km}$.

\subsection{Parameters of seismic intensity adopted in the study}

Neglecting the stiffening effect of non-structural curtain walls, precast RC buildings located in the area typically show a fundamental period lying in the range 1-2 seconds (Bournas et al. 2014). In fact, the presence of curtain walls provided with strip windows, generally located in correspondence of the building perimeter, may lead to severe structural damages (see Section 5), but, especially in buildings with non-rigid roof slab and a very large dimension in plan, does not influence significantly the global behaviour in the direction orthogonal to that dimension. For a typical building layout see for example Fig. 6 of the paper by Bournas et al. (2014).

In order to state a relationship between damages and ground motion intensity, the horizontal PSA at $1 \mathrm{~s}$ with a 5\% damping ratio was used (subscript "h" is dropped for simplicity of notation). The vertical component of the ground motion was not considered in the present study, because it affects particularly structures with very low natural periods.

The PSA data were obtained from the shakemaps published online by INGV (2012), and computed using the ShakeMap software package (Wald et al. 2006). That software was implemented by INGV to be used automatically in real time for Civil Protection purposes (Michelini et al. 2008). For all earthquakes with magnitude $\mathrm{M}_{\mathrm{L}} \geq 3.0$, maps of macroseismic intensities in terms PSA (but also PGV and PGA) are computed by INGV for the post-earthquake emergency management and, with regard to the industrial buildings hit by the 2012 Emilia earthquakes, they were also widely used to define the intervention strategies (Braga et al. 2014). Values of PSA were provided by INGV only for the periods $0.3,1$, and $3 \mathrm{~s}$. Then, the period of $1 \mathrm{~s}$ 


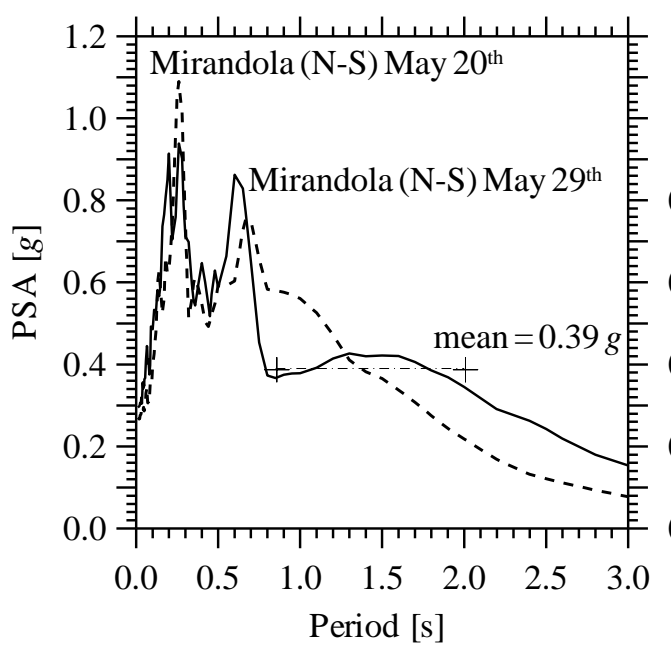

(a)

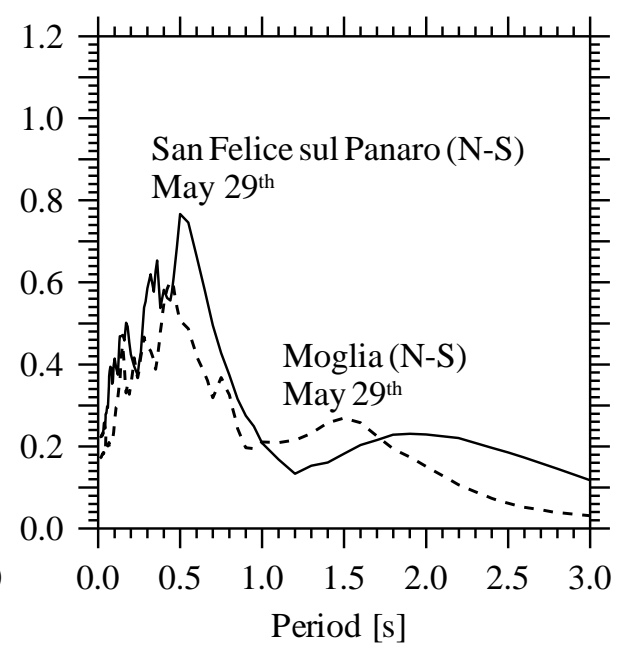

(b)

Fig. 1 Horizontal PSA versus period for (a) the seismic station at Mirandola (first and second mainshocks), and (b) those at San Felice sul Panaro and Moglia (second mainshock)

was selected in the present study as the closest to the main vibration period of the buildings. Anyway, at least for the spectra of the records collected during the second mainshock, PSA at $1 \mathrm{~s}$ represents a good approximation of the mean value of the PSA in the interval 0.85-2 s (see Fig. 1).

Only the shakemaps of the two mainshocks (May 20 ${ }^{\text {th }}$ and $29^{\text {th }}$ ) were considered in the present study. In particular, for each building examined and included into the database, the value of PSA at $1 \mathrm{~s}$ corresponding to the nearest epicentre was retained. For comparison, also the maximum experienced PGA was considered. Because the strong motion data provided by INGV are referred to a dense grid with nodes spacing $1 \mathrm{~km}$, according to the rule suggested by the Italian Building Code (2008), PGA and PSA at a given location in the map were obtained as the weighted mean values of the ground motion intensity measures at the four closest grid nodes, with the $i$-th weight being the reciprocal of the distance between the location and the $i$-th node. Only 409 of the 1421 buildings included into the database are located closer to the epicentre of the first mainshock. For the remaining 1012 buildings, the PSA at $1 \mathrm{~s}$ was that corresponding to the second mainshock.

The PSA of the two mainshocks presents some peculiar feature. For example, the PSA at $1 \mathrm{~s}$ obtained from the records of the seismic station of Mirandola for the first and second mainshocks was (INGV 2012) $5.50 \mathrm{~m} / \mathrm{s}^{2}(0.56 \mathrm{~g})$ and $3.70 \mathrm{~m} / \mathrm{s}^{2}(0.38 \mathrm{~g})$, respectively (see Fig. 1(a)). A value of PSA 50\% larger for the May $20^{\text {th }}$ mainshock appears quite unusual for two reasons: (1) the second mainshock was recorded at a much smaller epicentral distance, and (2) the magnitudes of the two mainshocks were comparable and no significant site effect can be expected in the area. With regard to the spectrum of the N-S component recorded during the first mainshock (Fig. 1(a)), a PSA at $1 \mathrm{~s}$ approximately equal to three times the PSA at $2 \mathrm{~s}$ is observed. However, the heavy damages observed in the area around Mirandola were caused mainly by the second mainshock.

Cultrera et al. (2014) showed that the increase in the number of stations between the two mainshocks led to a significant improvement of the ground motion estimates. Due to the small number of recording stations available during the first mainshock, the shakemaps of PGA and PSA at $3 \mathrm{~s}$ may be underestimated of about $0.20 \mathrm{~g}$ and $0.14 \mathrm{~g}$, respectively, whereas, with the dense 
station coverage for the May $29^{\text {th }}$ earthquake, the error reduces to about $0.10 \mathrm{~g}$ and $0.05 \mathrm{~g}$, respectively. Underestimates of PGA were also underlined by Braga et al. (2015).

\section{Recurrent damages and collapses in precast industrial buildings}

The two mainshocks caused extended damages and collapses in prefabricated RC buildings. In some industrial areas close to the epicenters (e.g., Mirandola Nord, S. Giacomo Roncole, Cavezzo, Medolla), up to $70 \%$ of buildings were significantly damaged or collapsed. Most of the damages were related to the absence of appropriate connections between precast elements assembled in simply-supported conditions (slab-to-beam support, beam-to-column connection) and to the insufficient steel reinforcement in the columns. The interactions with non-structural elements and the rotational flexibility of foundations, when the precast pocket foundation technology was adopted, were also important causes of collapses. Moreover, older buildings with masonry curtain walls between RC columns (with the walls supporting most of the horizontal loading during the earthquake) and more recent buildings with external RC cladding panels (where horizontal forces mainly act on precast columns in clamped-free condition) exhibited very different seismic responses (Savoia et al. 2012). Some pictures of the most frequent collapses and damages are reported in Figs. 2-6 and described in the following.

Fig. 2(a) shows the falling of a precast beam from the column support due to the interaction with the front masonry curtain wall. During the roof oscillation, the infill wall alternatively exerted an additional constraint to only one of the two adjacent columns, leading to a significant increase in the translational stiffness of that column. Therefore, most of the horizontal force was transferred to one beam-column support only, overcoming the friction capacity of the support. This failure was very common in buildings with strip windows between the precast beam and the curtain wall. Fig. 2(b) shows an extended roof collapse in a modern precast building due to the absence of slabbeam connections.

Fig. 3 shows the falling of curtain walls. In the case of Fig. 3(a), the collapse of the masonry curtain wall was caused by the insufficient restraint exerted on the wall by RC columns and upper beam, due to the presence of the strip window. Sometimes, before the collapse of the masonry

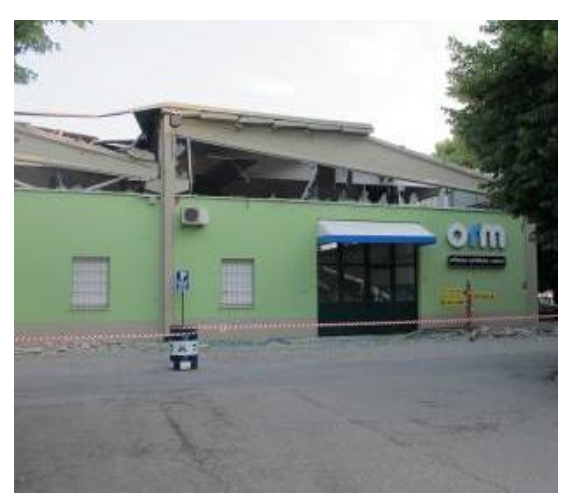

(a)

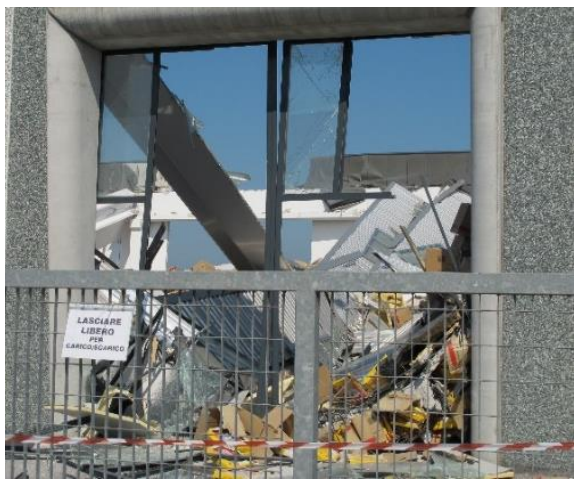

(b)

Fig. 2 Roof collapses in precast buildings: (a) partial collapse due to interaction with masonry curtain walls; and (b) extended collapse in a modern prefabricated building 


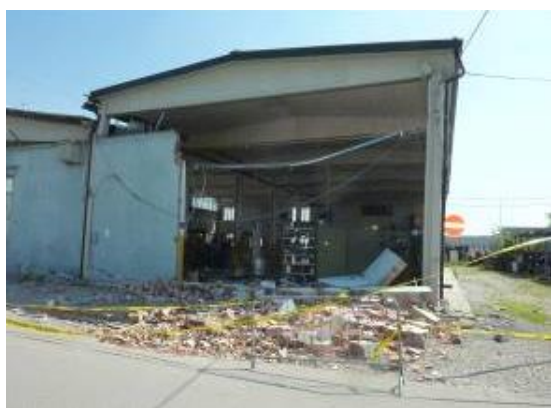

(a)

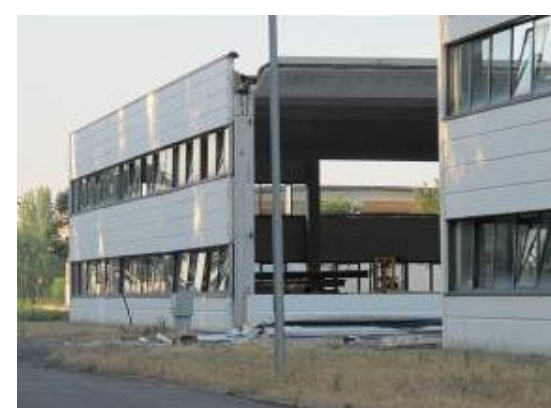

(b)

Fig. 3 Collapse of (a) a masonry curtain wall not restrained by the RC structure; and of (b) RC cladding panels due to failure of the steel channel profiles supporting them

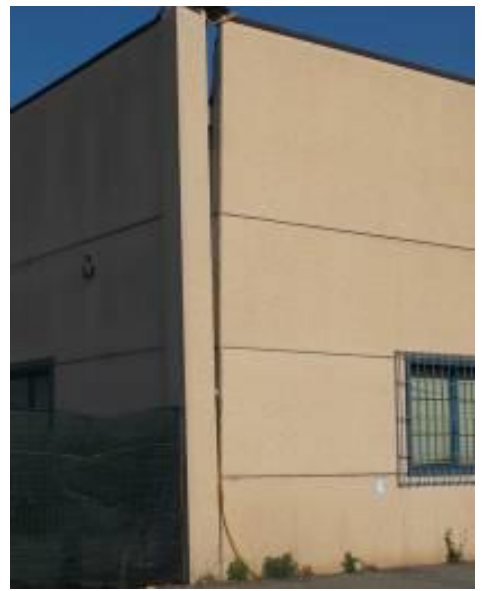

(a)

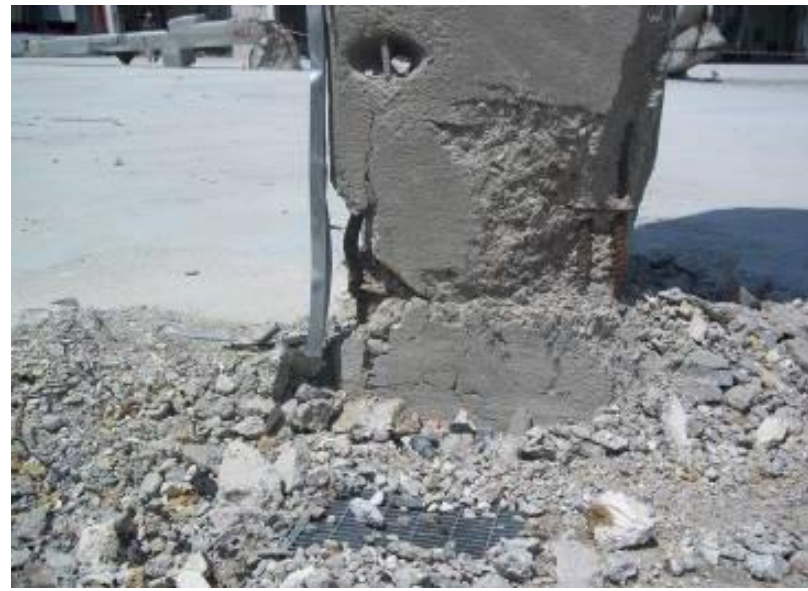

(b)

Fig. 4 Damages in precast RC columns: (a) rotation of external columns; and (b) large base rotation due to formation of a plastic hinge with yielding and buckling of longitudinal steel bars

infill, column damages occurred because of the interaction with the wall: in Fig. 3(a), note also the short column failure of the left column. Short column failure mechanisms were also documented in Figs. 11-13 reported by Liberatore et al. (2013), and in Fig. 10 reported by Bournas et al. (2014). The picture of Fig. 3(b) illustrates the falling of RC cladding panels due to the damage of the retaining systems, represented by steel channel profiles cast in the column concrete cover. These devices are typically designed against horizontal forces acting perpendicularly to the panels and are not able to support the large building displacements in the direction parallel to the curtain front during the earthquake. This kind of collapse was common in precast buildings with horizontal cladding panels.

Rotations of precast $\mathrm{RC}$ columns not designed for the earthquake resistance due to damages at the column base are shown in Fig. 4. In the case of Fig. 4(a), the rotation was caused by the formation of a plastic hinge at the base. A detail of a plastic hinge, with yielding of longitudinal steel bars in tension and buckling of bars in compression is shown in Fig. 4(b).

Local damages occurred frequently in columns due to the interaction with masonry curtain 
walls (Fig. 5(a)), or in the forked supports at the column top (Fig. 5(b)), generally not designed to avoid overturning of the beams during seismic excitations. Typically, these damages were repairable and were restricted to some elements in the building only.

Sometimes, rigid rotations of columns occurred due to settlements at the foundation level or failure of the precast sleeve footing. In few cases, very large column rotations occurred with very extended collapses (Fig. 6(a)), probably due to the use of fully precast sleeve footings simplysupported on the cast in situ RC foundation. This technology was often used in recent years in order to speed up the construction, but this kind of foundation structure does not exhibit any overstrength capacity when the external bending moment overcomes the stabilizing moment. In other cases, the presence of a RC pavement avoided excessive column rotation and falling of the upper beam (Fig. 6(b)). With regard to the overturning failure of precast RC columns, an analysis was recently presented by Kafle et al. (2015).

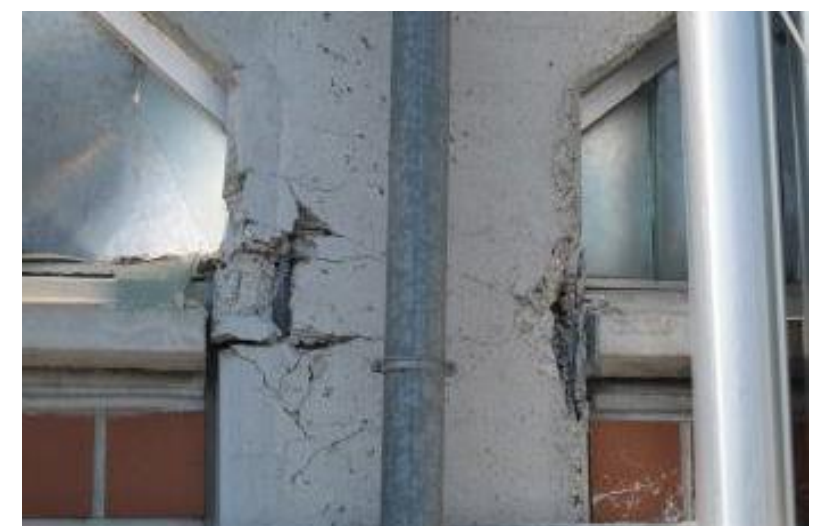

(a)

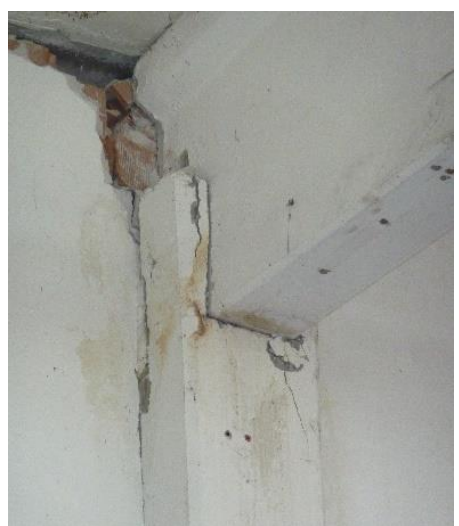

(b)

Fig. 5 Local damages in precast RC columns: (a) failure mechanism due to interaction with masonry infills; and (b) damage of the upper fork of a column due to flexural-torsional displacements of the precast beam

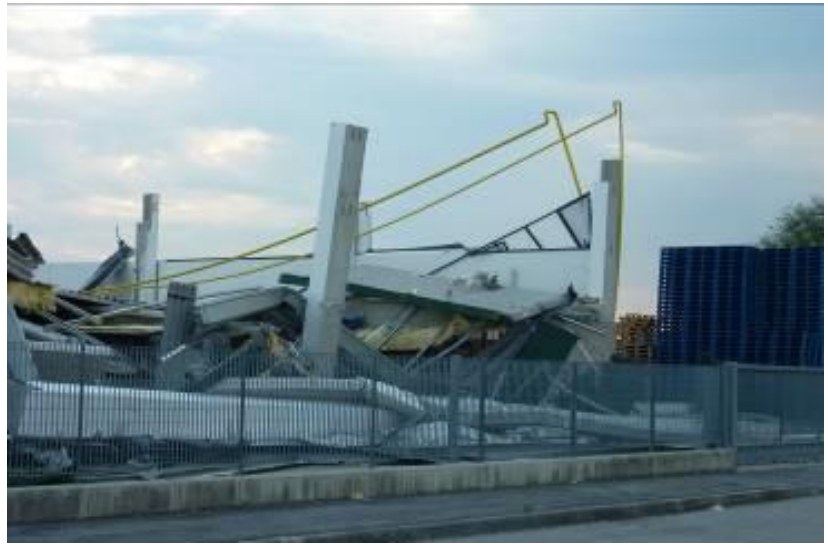

(a)

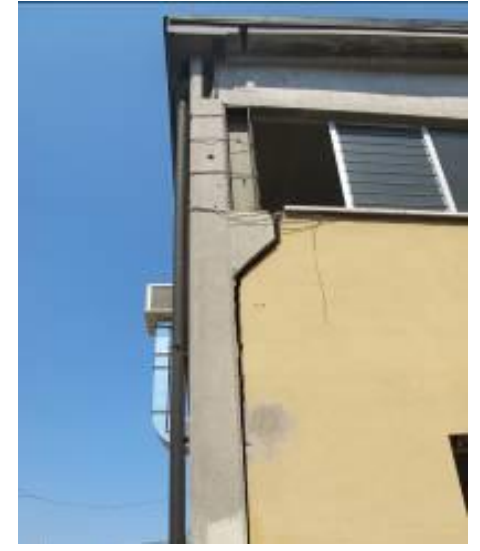

(b)

Fig. 6 Damages in precast RC columns: (a) extended building collapse caused by large column rotation due to foundation settlement; and (b) column rotation due to settlement at the foundation level, counteracted by the presence of an industrial concrete pavement 


\section{Damage data collection and inventory}

After an earthquake, the collection of damage data and their inventory represent an essential tool for predicting the response of the buildings to future earthquakes.

The post-earthquake survey procedures usually adopted worldwide are rapid assessment protocols for assisting the surveyors in making a decision about the usability of the buildings based on the observed damages. In Italy, the official protocol was developed from the experience acquired since the 1997 Umbria-Marche earthquake, and combines observational damage data with information on possible sources of seismic risk. This procedure is based on AeDES inspection form (Baggio et al. 2007) and is restricted to ordinary buildings. As far as the precast industrial buildings struck by the 2012 Emilia earthquakes, designed in most cases without any seismic design criteria, are concerned, this protocol was not applicable at all. In fact, the absence of mechanical connections between the precast elements caused many very brittle failures, often without any preceding damage indicating the possible vulnerability of the structure. This aspect became particularly evident after May $29^{\text {th }}$ mainshock, that caused heavy damages and collapses even to buildings which did not suffer any damage during May $20^{\text {th }}$ mainshock, even if the first earthquake was characterized by comparable and even larger values of some macroseismic parameters (see Section 2.2).

As an example, two pictures of a single-storey two-bay industrial building with variable height roof beams simply-supported in correspondence of the columns and perimeter masonry curtain walls, taken after the first and the second mainshock, are reported in Fig. 7(a) and Fig. 7(b), respectively. The maximum accelerations in that area were comparable, but the effects of the second mainshock on many buildings were significantly heavier. In that building, May $20^{\text {th }}$ earthquake caused only the detachment of a masonry curtain wall on the front without any displacement between beams and columns at the roof level. On the contrary, May $29^{\text {th }}$ earthquake caused the falling of the two front beams with a mechanism analogous to that shown in Fig. 2(a).

The field surveys highlighted the following main sources of seismic vulnerability for the precast industrial buildings, additional with respect to the cast-in-situ RC structures:

- the lack of connecting devices between precast monolithic elements, and in particular between roof slab elements and main girders and between main girders and columns;

- the inadequacy of steel connections of precast RC cladding panels to the structural elements (i.e., columns and beams);

- the presence of very heavy shelves without any bracing systems suitable for resisting horizontal forces.

The aforementioned shortcomings being the cause of a huge number of partial or full collapses, their removal, even for undamaged buildings, became mandatory after the second mainshock in 52 municipalities close to the epicentre, in order to allow for restarting the working activities (Legislative Decree No. 74/2012). In particular, a two-phase intervention strategy was planned. In the first short term phase, interventions aimed at removing the three mentioned vulnerabilities had to be scheduled in order to re-obtaining the temporary usability of the buildings. The second long term phase required seismic risk assessment and, if necessary, the design of structural retrofitting interventions. According to Legislative Decree No. 74/2012 (2012), the retrofitting interventions shall ensure a safety level not lower than $60 \%$ of that required for a new construction.

In the present study, in the absence of inspection forms dedicated to precast industrial buildings, the damage data were collected from survey reports prepared by structural engineers charged of estimating the damages as a preliminary phase for the design of retrofitting 


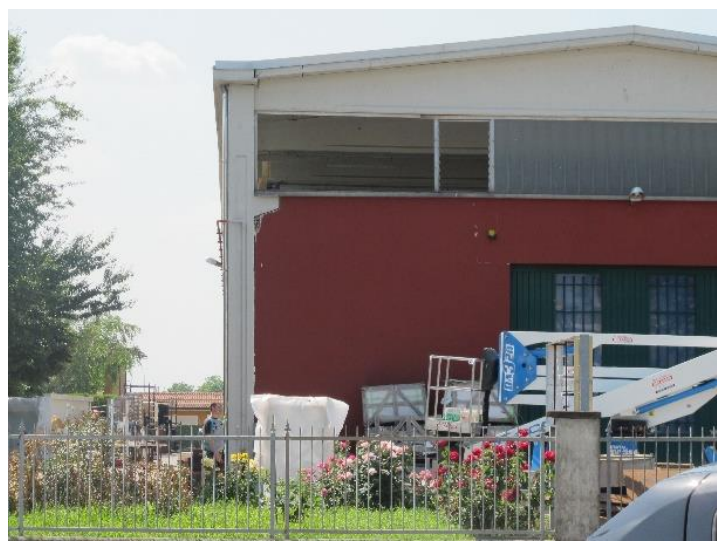

(a)

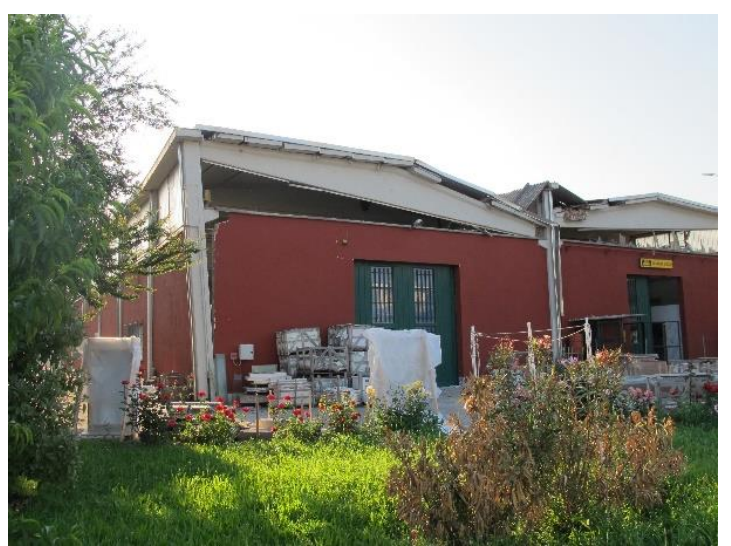

(b)

Fig. 7 Industrial building in San Giacomo Roncole (Mirandola, MO): (a) the building after May 20 th earthquake, and (b) after May $29^{\text {th }}$ earthquake

Table 1 Damage levels adopted in the present investigation and correspondences with definitions reported by Emilia-Romagna Regional Decree No. 57/2012

\begin{tabular}{ccccccc}
\hline Damage level & D0 & D1 & D2 & D3 & D4 & D5 \\
\cline { 2 - 7 } & $\begin{array}{c}\text { No } \\
\text { damage }\end{array}$ & $\begin{array}{c}\text { Slight } \\
\text { damage }\end{array}$ & $\begin{array}{c}\text { Moderate } \\
\text { damage }\end{array}$ & $\begin{array}{c}\text { Severe } \\
\text { damage }\end{array}$ & $\begin{array}{c}\text { Heavy } \\
\text { damage }\end{array}$ & Collapse \\
\hline $\begin{array}{c}\text { Damage class according to } \\
\text { Regional Decree 57/2012 }\end{array}$ & & c & b & d & e & a \\
$\begin{array}{c}\text { Local or distributed structural damages to } \\
\text { horizontal and/or vertical partitions without } \\
\text { collapses }\end{array}$ & - & $<20 \%$ & $\geq 20 \%$ & - & - & - \\
$\begin{array}{c}\text { Severe structural damages to horizontal } \\
\text { and/or vertical external surfaces with } \\
\text { collapses }\end{array}$ & - & - & - & $\leq 15 \%$ & $\leq 30 \%$ & $>30 \%$ \\
$\begin{array}{c}\text { Residual column drift } \\
\theta>2 \%{ }^{3}\end{array}$ & - & - & - & $\begin{array}{c}\text { atleast 1 } \\
\text { column }\end{array}$ & $\leq 20 \%$ & $>20 \%$ \\
Plastic hinges at the column base sections & - & - & - & - & $\leq 20 \%$ & $>20 \%$ \\
\hline
\end{tabular}

${ }^{1}$ Percentages referred to all horizontal and vertical partitions in the building

${ }^{2}$ Percentages referred to all horizontal and vertical outer surfaces in the building, such as roof and curtain walls

${ }^{3}$ Percentages referred to the whole number of columns in the building

Table 1 Correspondence of the damage levels used in the present analysis with those introduced by EMS-98 (1998)

\begin{tabular}{cccccccc}
\hline \hline \multicolumn{2}{c}{ Damage scale } & \multicolumn{2}{c}{ Damage level } & & & & \\
\hline & Present & D0 & D1 & D2 & D3 & D4 & D5 \\
\hline \multirow{2}{*}{ EMS-98 } & $\begin{array}{c}\text { Non-structural } \\
\text { damage }\end{array}$ & - & Slight & Moderate & Heavy & $\begin{array}{c}\text { Very } \\
\text { heavy }\end{array}$ & $\begin{array}{c}\text { Total or } \\
\text { partial } \\
\text { collapse }\end{array}$ \\
\hline
\end{tabular}


interventions. These reports were also validated by a public in-house company charged of assessing the coherence of the public economical contribution for the interventions. Of course, data collection was much slower than using data from post-earthquake inspection forms, but its quality was significantly better.

Damage data were classified according to the six level damage scale reported in Table 1, from the absence of both structural and non-structural damages (level D0) up to building collapse (level D5). These levels substantially coincide with those introduced by EMS-98 (1998), reported in Table 2 for comparison. Furthermore, levels D1 (slight damage), D2 (moderate damage), D3 (severe damage), D4 (heavy damage) and D5 (collapse) considered in the present analysis correspond to damage classes "c", "b", "d", "e" and "a", respectively, established by Decree No. 57/2012 (2012) of Emilia-Romagna region. In particular, the latter diversifies the damage classes according to the percentage of damaged elements (i.e., slabs, roof, including the supporting beams, and cladding panels) and damaged columns (Table 1).

Earthquake-induced foundation settlements are also considered by the recent updates of Regional Decree No. 57/2012, but they do not appear explicitly in Table 1. As a matter of fact, rotations of the pocket foundation at the column base, observed in some cases (Fig. 6), may be taken into account in the form of a permanent column drift.

Regional Decree No. 57/2012 granted specific non-repayable funds to the manufacturing companies for the interventions on damaged buildings. In particular, the funds dedicated to buildings belonging to damage levels D1 and D2 covered the costs for local repair interventions and structural strengthening, and could be increased to cover the seismic retrofitting. Funds for severely and heavily damaged buildings (levels D3 and D4) covered all the refurbishment costs, including seismic retrofitting. Funds for partially or fully collapsed buildings (level D5) covered reconstruction costs. Finally, for undamaged buildings (level D0), financial support to realize short term interventions (e.g., connecting devices at the roof or slab level to avoid sliding of monolithic elements), but also for seismic retrofitting, was periodically made available (Emilia-Romagna Regional Decree No. 91/2013).

The purpose of the classification reported by Regional Decree No. 57/2012 was to provide for objective elements for the evaluation of damages, being the damage level strictly connected with the funding plateau. However, establishing the damage level of buildings according to Table 1 may result in unconservative damage evaluations. For instance, damage levels D3, D4 and D5 depend on the number of columns whose permanent drift is greater than $2 \%$, but it can be verified that, for precast buildings, this value is too large to be related to a damage condition measured at the end of the seismic event. In fact, for RC columns, a drift of $2 \%$ is a typical value usually provided (see Table C1-3 of FEMA 356 2000) to illustrate the overall structural response associated with a Life Safety Structural Performance Level, and is therefore related to the maximum drift attained during the seismic event. Thus, a value of the residual drift lower than $2 \%$ should be used for identifying the damage level at the end of the seismic event. For example, taking second order effects into account according with the nominal curvature method (CEN 2004), it is possible to show that precast RC columns of industrial buildings typical for the struck area, and not designed for the earthquake resistance, can collapse under permanent loads in the presence of a residual drift of approximately $1 \%$. Such a drift value should then be considered as a very heavy damage. Hence, as far as damages related to residual column drifts larger than $2 \%$ are concerned, damage levels D3, D4 and D5 defined in Table 1 can be considered as substantially equivalent. 


\section{Damage data analysis}

In the present study, the damage data for the 1421 buildings examined were processed to obtain correlations between damage level and epicentral distance or, alternatively, PSA at $1 \mathrm{~s}$. In particular, with reference to the earthquakes occurred on May $20^{\text {th }}$ and $29^{\text {th }}$, the distance from the nearest epicentre and corresponding PSA at $1 \mathrm{~s}$ were considered for each building. Table 3 shows, for each of the 5 damage levels, the number of buildings included into the database. About $96 \%$ of these buildings (1358 over 1421) are located at no more than $30 \mathrm{~km}$ from the nearest epicentre and, in such range of epicentral distances, they represent approximately $30 \%$ of the whole number of precast industrial buildings struck by the seismic sequence. For epicentral distances larger than $30 \mathrm{~km}$, the data reported in the database are not significant because only few buildings were subjected to survey so far from the epicentres.

Table 2 Number of buildings included into the database for each damage level

\begin{tabular}{cccccccc}
\hline \hline Damage level & D0 & D1 & D2 & D3 & D4 & D5 & D1+..+D5 \\
\hline No. of buildings in the database & 801 & 196 & 125 & 82 & 54 & 163 & 620 \\
\hline
\end{tabular}

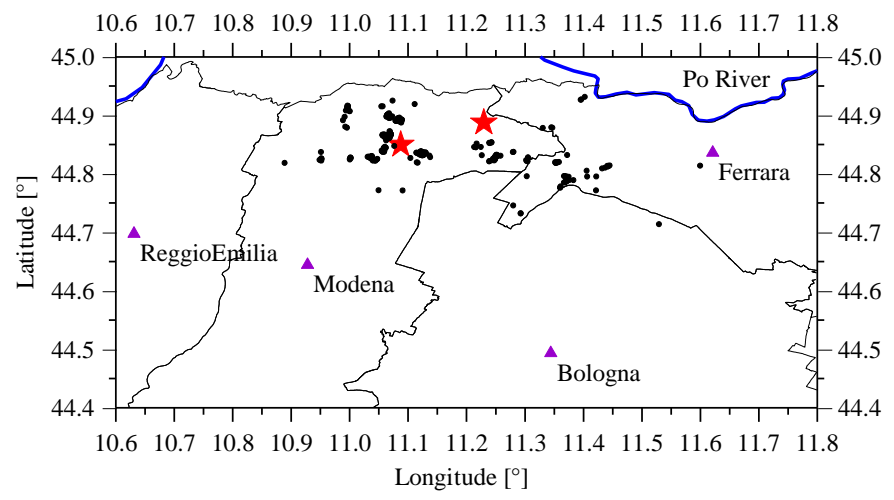

Fig. 8 Map reporting the locations of 299 severely damaged to collapsed buildings (damage levels D3, D4 and D5, black data points) and of epicentres of the two mainshocks (red stars)

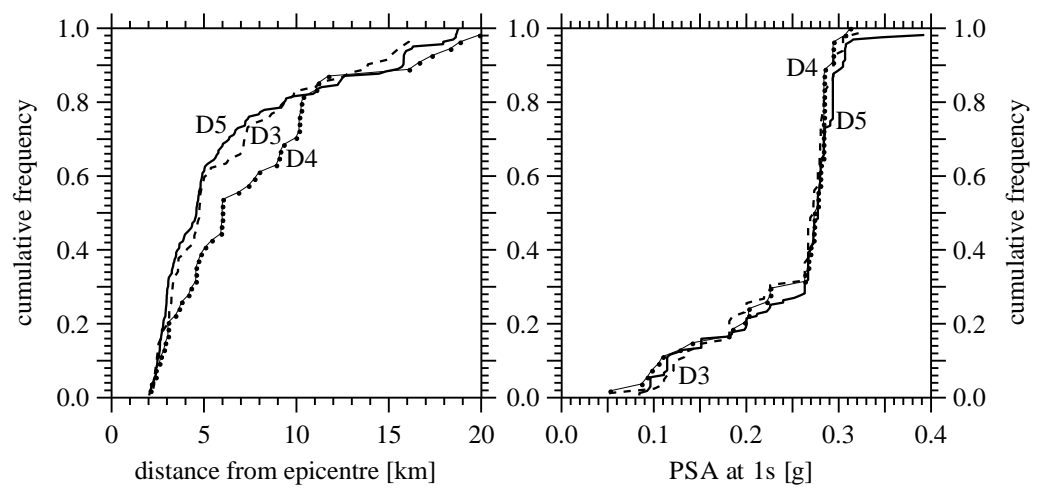

(a)

(b)

Fig. 9 Cumulative frequencies of buildings belonging to damage levels D3 (dashed lines), D4 (line with symbols) and D5 (solid line) versus (a) distance from the nearest epicentre, and (b) corresponding PSA at $1 \mathrm{~s}$ 
The locations of the industrial buildings belonging to damage levels D3, D4 and D5 are reported in Fig. 8, where the highest concentration is observed around the epicentre of May $29^{\text {th }}$ earthquake $\left(M_{L}=5.8\right)$. Several buildings with heavy damages are also located at South-East of May $20^{\text {th }}$ earthquake $\left(\mathrm{M}_{\mathrm{L}}=5.9\right)$ epicentre. The cumulative frequencies of buildings with damage levels D3, D4 and D5 are reported in Fig. 9(a) and Fig. 9(b) versus epicentral distance and PSA at $1 \mathrm{~s}$, respectively. For each damage level, the cumulative frequency is referred to the total number of buildings belonging to that level and included into the database, i.e., 82, 54 and 163 buildings for damage levels D3, D4 and D5, respectively (see Table 3). All collapsed buildings are located at less than $19 \mathrm{~km}$ from the nearest epicentre, and for $80 \%$ of them the epicentral distance does not exceed $9 \mathrm{~km}$ (D5 in Fig. 9(a)). Moreover, 80\% of the collapsed buildings experienced a PSA larger than $0.26 \mathrm{~g}$ (D5 in Fig. 9(b)). It is worth noting that, in Fig. 9, the curves corresponding to damage levels D3 and D4 are very close to those corresponding to damage level D5, so confirming the difficulty, for the technicians charged of preparing the damage reports, of distinguishing between the three damage levels. This behaviour justifies the grouping of the three damage levels into one single damage class, as will be carried out in the following.

The locations of the buildings with slight to moderate damages (levels D1 and D2) are reported in Fig. 10, where they appear scattered over the struck area, with the highest density in the Modena county. For the same buildings, the plots of the cumulative frequencies versus distance from the nearest epicentre and corresponding PSA at $1 \mathrm{~s}$ are reported in Fig. 11(a) and Fig. 11(b), respectively. The cumulative frequencies for damage levels D1 and D2 are referred to 196 and 125 buildings, respectively (Table 3 ). All buildings with moderate damages lie at an epicentral distance not larger than $26 \mathrm{~km}$, and $20 \%$ of them are located at less than $5 \mathrm{~km}$ from the nearest epicentre (D2 in Fig. 11(a)). Moreover, 20\% of the buildings with moderate damages experienced a PSA larger than $0.28 \mathrm{~g}$ (D2 in Fig. 11(b)). Finally, for $20 \%$ of the buildings with slight damages, the minimum epicentral distance does not exceed $7 \mathrm{~km}$ (D1 in Fig. 11(a)), and the experienced PSA at $1 \mathrm{~s}$ is larger than $0.27 \mathrm{~g}$ (D1 in Fig. 11(b)).

The 801 undamaged buildings included into the database (Table 3) are indicated in the map of Fig. 12, where they appear almost uniformly distributed within the counties of Reggio Emilia, Modena, Bologna and Ferrara, and then also close to the earthquake epicentres. Note that only buildings lacking appropriate connections between precast elements and located in the struck area of Emilia-Romagna region were considered in the database.

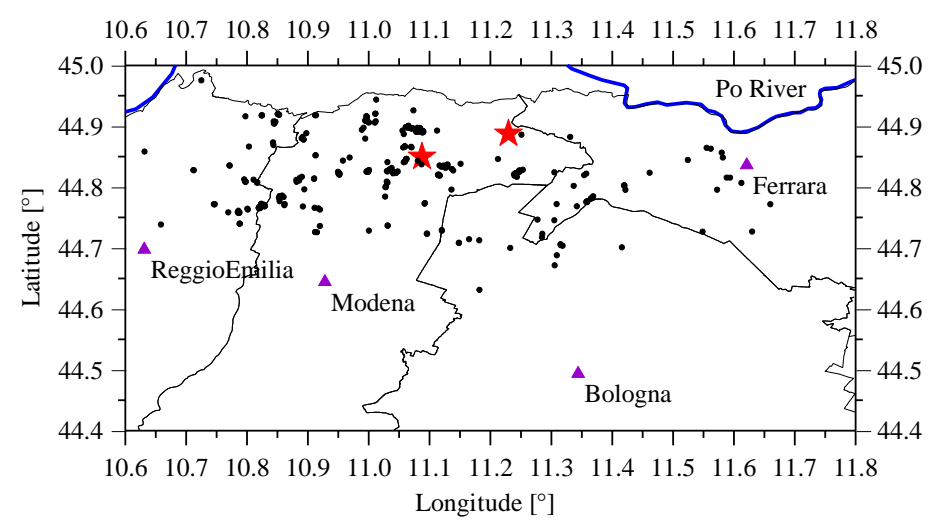

Fig. 10 Map reporting the locations of 321 slightly to moderately damaged buildings (damage levels D1 and D2, black data points) and of epicentres of the two mainshocks (red stars) 


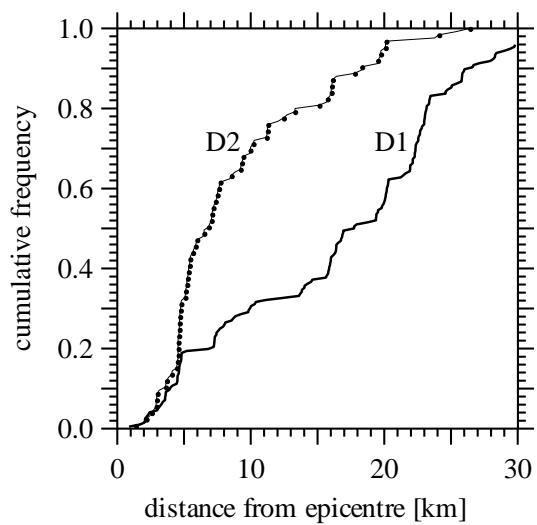

(a)

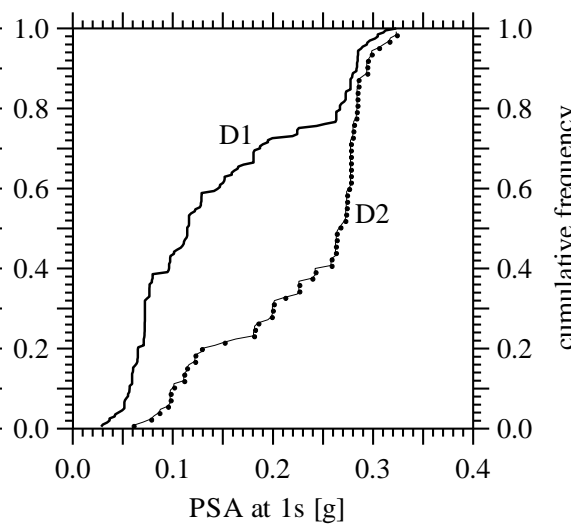

(b)

Fig. 11 Cumulative frequencies of buildings belonging to damage levels D1 and D2 versus (a) distance from the nearest epicentre, and (b) corresponding PSA at $1 \mathrm{~s}$

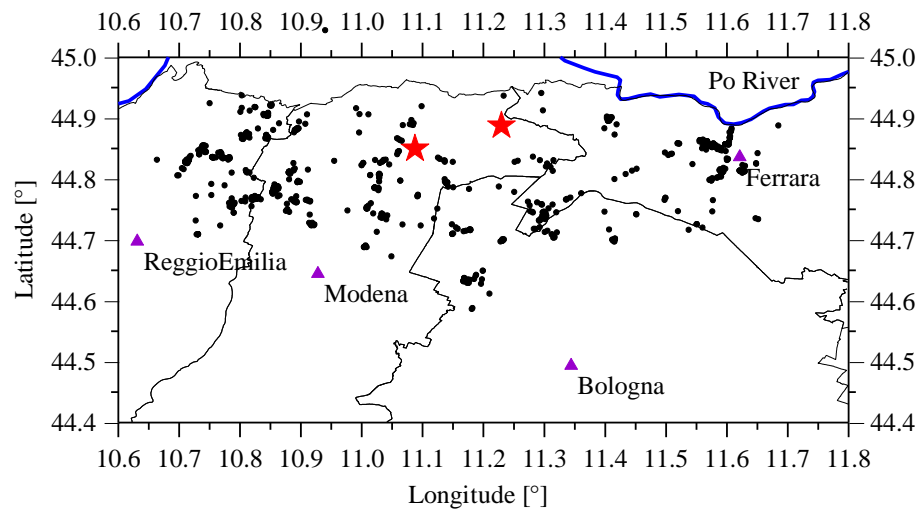

Fig. 12 Map reporting the locations of 801 undamaged buildings (damage level D0, black data points) and of epicentres of the two mainshocks (red stars)

The data reported show that even though six damage levels have been identified, the classification in one level or another may depend on the subjective judgement of the inspector.

For instance, the distinction between the distributions of buildings with damage levels D3, D4 and D5 is not clear (see Fig. 9).

Sometimes, also the distinction between damage levels D1 and D2 may be difficult. On the contrary, the distributions of groups of damage levels D3 to D5, D1 to D2, and D0 are clearly distinct (see Figs. 8, 10 and 12). Therefore, in the further analyses, the damage data were grouped into three main classes, i.e., the class of the undamaged buildings (D0), that collecting the buildings with slight to moderate damages $(\mathrm{D} 1+\mathrm{D} 2)$, and, finally, that of the severely damaged to collapsed buildings (D3+D4+D5). The corresponding cumulative frequencies, referred to 801, $196+125=321$, and $82+54+163=299$ buildings, respectively (see Table 3), are reported in Fig. 13 versus the distance from the nearest epicentre. It can be noted from Fig. 13 that $90 \%$ of the severely damaged to collapsed buildings (D3+D4+D5) lie within $16 \mathrm{~km}$ from the nearest epicentre. Moreover, for $90 \%$ of the buildings with slight to moderate damages $(\mathrm{D} 1+\mathrm{D} 2)$, the minimum epicentral distance is less than $25 \mathrm{~km}$. 
Finally, the undamaged buildings are almost uniformly distributed over the struck area, confirming the result reported on the map of Fig. 12. In fact, the red curve reported in Fig. 13, substantially coincident with the frequency-distance plot for the undamaged buildings, represents a quadratic function of the form

$$
F_{\mathrm{D} 0}\left(R_{\mathrm{epi}}\right)=\mathrm{C} \pi R_{\mathrm{epi}}^{2}
$$

following from the assumption of uniform building density. In Eq. (1), $R_{\text {epi }}=$ generic epicentral distance in $\mathrm{km}$; and $\mathrm{C}=3.25 \times 10^{-4}$ is a constant obtained from data fitting. Of course, very close to the epicentres a smaller number of undamaged buildings, and a deviation of Eq. (1) from the data, can be expected. Nevertheless, the circumstance that also quite close to the epicentres there is a significant number of undamaged buildings indicates that some precast building typologies did not suffer damages also in the presence of large ground accelerations.

The data are presented in an alternative form in Fig. 14, to underline the percentages of buildings with different levels of damage as a function of their epicentral distance. In particular, the cumulative sum of buildings investigated is reported in Fig. 14(a), whereas the percentage distribution of the buildings belonging to the three damage classes is reported in Fig. 14(b). The 1358 investigated buildings with $R_{\text {epi }} \leq 30 \mathrm{~km}$ are distributed among the three damage classes according to the following percentages: 22\% (D3+D4+D5), 23\% (D1+D2) and 55\% (D0). The buildings with severe damages up to collapse (D3+D4+D5 in Fig. 14(b)) are $62 \%$ of all buildings in the range $0-5 \mathrm{~km}$, and about one half of the total stock for epicentral distances up to $10 \mathrm{~km}$. Nevertheless, it is worth noting that $19 \%$ of the buildings within $10 \mathrm{~km}$ from the epicentre did not suffer any damage (D0 in Fig. 14(b)).

The cumulative frequencies of the buildings belonging to the different classes of damage levels are reported in Fig. 15(a) versus the PSA at $1 \mathrm{~s}$ corresponding to the nearest epicentre. It can be observed that $90 \%$ of buildings with severe damages up to collapse (D3+D4+D5) experienced a PSA larger than $0.12 \mathrm{~g}$ and $10 \%$ of them was subject to a PSA larger than $0.29 \mathrm{~g}$. Moreover, $90 \%$ of buildings with slight to moderate damages (D1+D2) experienced a PSA larger than $0.06 \mathrm{~g}$.

Distributions of the damage classes D1+D2 and D3+D4+D5 similar to those reported in Fig. 15(a) are finally presented in terms of the maximum experienced PGA in Fig. 15(b). It is worth noting that these curves show a sudden slope change at $P G A \approx 0.28 \mathrm{~g}$, with a significant increase of

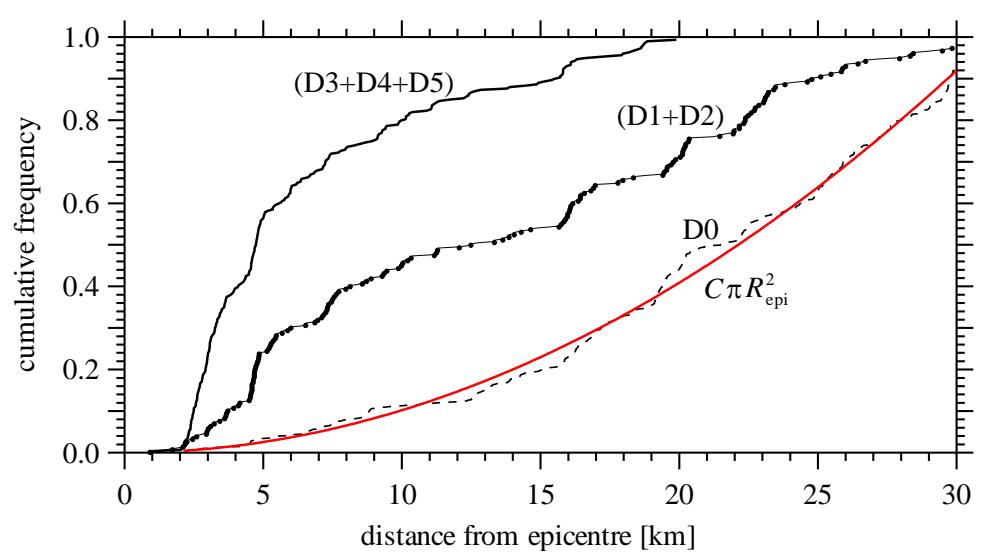

Fig. 13 Cumulative frequencies of the three classes of damage levels plotted versus the distance from the nearest epicentre 

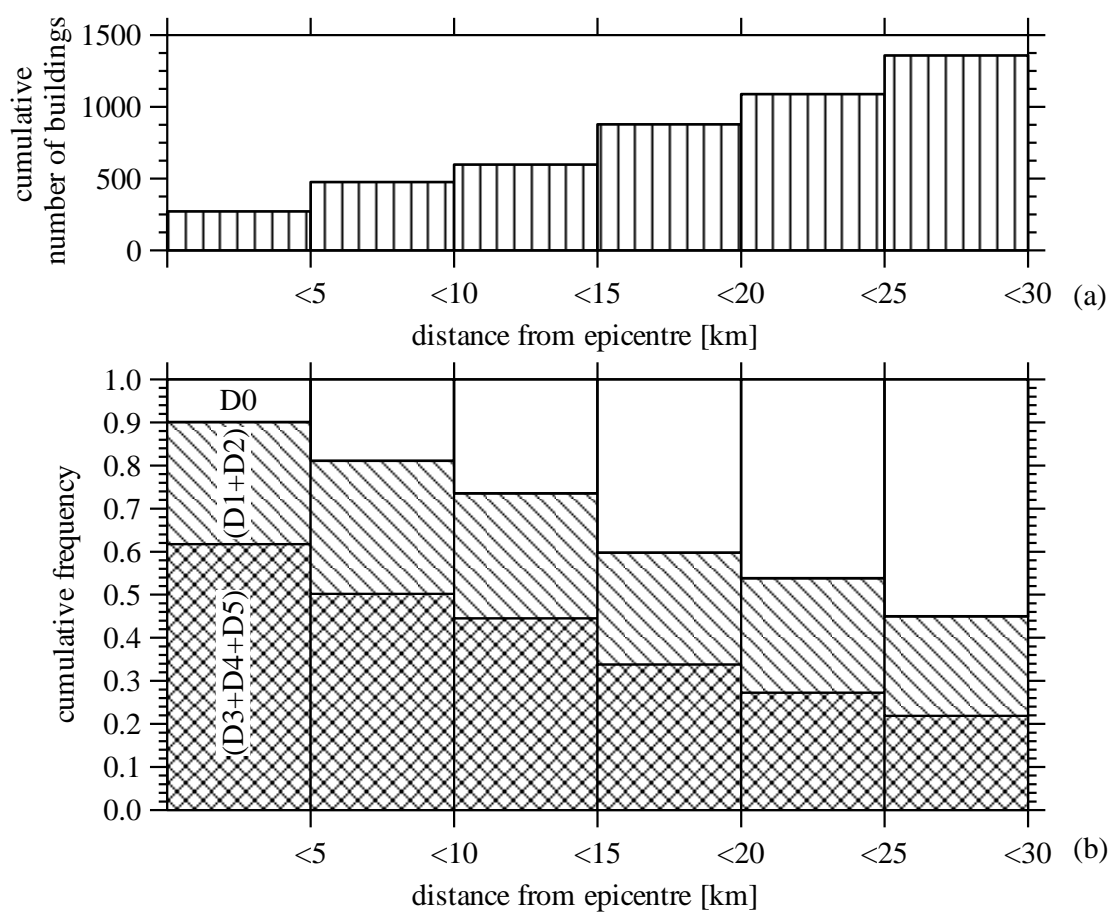

Fig. 14 Bar charts with (a) cumulative number of buildings investigated, and (b) cumulative frequencies of buildings versus epicentral distance for the three classes of damage levels

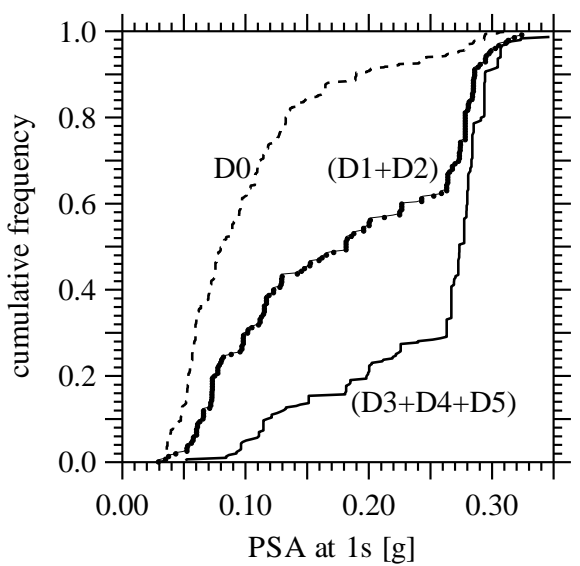

(a)

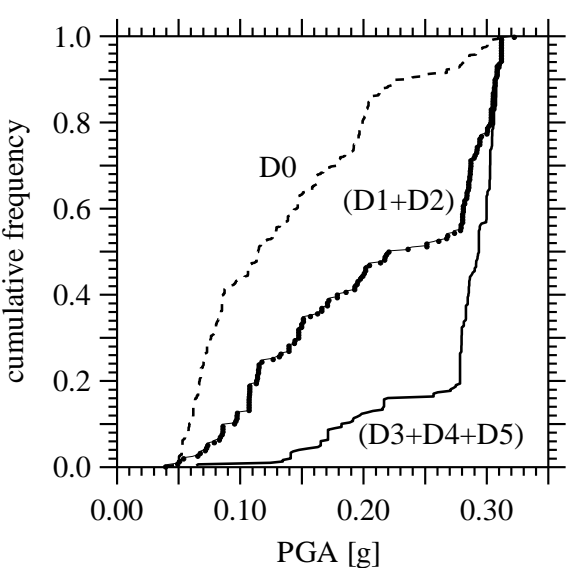

(b)

Fig. 15 Cumulative frequencies of the three classes of damage levels versus (a) PSA at $1 \mathrm{~s}$ corresponding to the nearest epicentre, and (b) maximum experienced PGA

the number of damaged buildings for PGA values greater than that value. In particular, the 442 buildings subjected to a $P G A \geq 0.28 \mathrm{~g}$ and located at epicentral distances lower than $12 \mathrm{~km}$ are distributed among the three damage classes according to the percentages reported in Table 4, showing a clear predominance of class D3+D4+D5 (severe damage to total collapse).

This circumstance would suggest the possibility that, for $\mathrm{PGA} \geq 0.28 \mathrm{~g}$, some damage 
mechanisms can be activated, depending on parameters not strictly related with the building characteristics: one of these causes can be the falling of the roof elements, or even main girders from their support (see Fig. 2(a)), which is related to the overcoming of the friction resistance at the support level. Actually, the slope changes shown in Fig. 15 are a consequence of the nonuniform distribution of buildings and of the spatial distribution of the parameters of seismic intensity. Only for the uniform distribution of the undamaged buildings (D0) the slope change is absent.

That said, the falling down collapse mechanism was very frequent in the epicentral areas, especially when the interaction between precast columns and non-structural walls took place.

As an example, consider a typical precast building with one single beam span and columns of height $h$. A general frame of the building is outlined in Fig. 16(a). According to Fig. 1(a), for a site which experienced a PGA of about $0.28 \mathrm{~g}-0.30 \mathrm{~g}$, and a natural period between $1 \mathrm{~s}$ and $2 \mathrm{~s}$, $\mathrm{PSA}=\alpha \mathrm{g}$, where $\alpha$ is about 0.4 . If $M$ indicates the upper mass (due to the presence of the roof slab elements and precast beam), the dead load acting on the two beam-column supports is $F_{v 1}=F_{v 2}=M g / 2$. The horizontal force due to the seismic excitation is then $F_{h}=M \mathrm{PSA}=\alpha M g$, and is equally divided between the two columns, i.e., $F_{h 1}=F_{h 2}=\alpha M g / 2$. It can then be verified that the supports are perhaps able to support the horizontal forces by friction, being $F_{h 1} / F_{v 1}=F_{h 2} / F_{v 2}=\alpha=0.4$, which is a typical value for the concrete-to-concrete friction coefficient (Tassios and Vintzēleou 1987). With an illustrative example considering a friction-based beam-column connection typical for the struck area, Liberatore et al. (2013), showed that, if no vertical component of the ground motion is considered, a friction coefficient $\alpha=0.4$ is sufficient to avoid relative displacements between beam and column. Conversely, sliding may occur in some case due to the combined effect of horizontal and vertical components of the ground motion.

Table 3 Distribution among the three damage classes of the buildings affected by a PGA $\geq 0.28 \mathrm{~g}$

\begin{tabular}{ccccc}
\hline \hline Damage class & D0 & D1+D2 & D3+D4+D5 & Total \\
\hline No. of buildings & 57 & 144 & 241 & 442 \\
Percentage [\%] & 13 & 32 & 55 & 100 \\
\hline
\end{tabular}

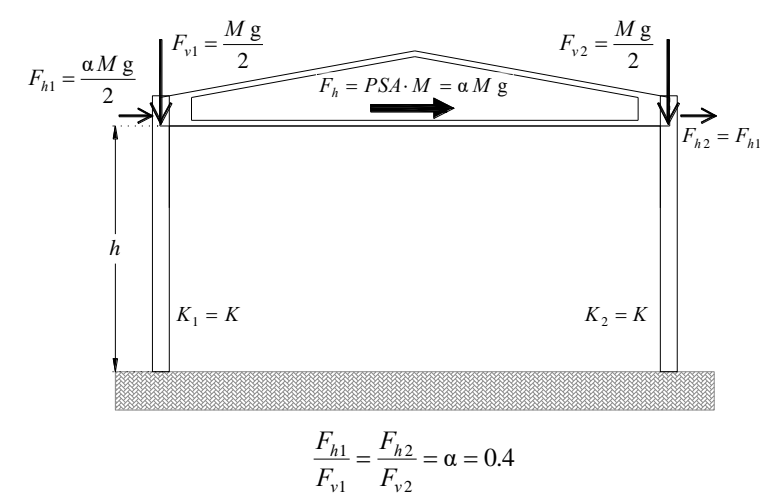

(a)

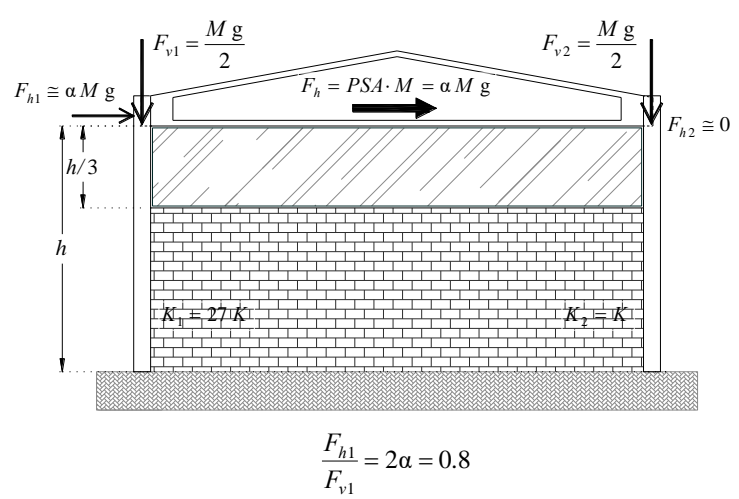

(b)

Fig. 16 Single-storey single-bay precast frame (a) without masonry infill and (b) with an infill wall provided with a strip window between precast beam and wall 
As a second case, consider a front frame with a masonry infill wall and a strip window on the top of it, whose height is $h_{1}=h / 3$ (see Fig. 16(b)). When the roof is oscillating due to the seismic excitation, the two columns exhibit different lateral stiffnesses because of the interaction with the infill: under the assumption that the left column has a deformable length equal to $h_{1}$, and thus behaves as a cantilever with the fixed cross-section located at $h-h_{1}=(2 / 3) h$ from the base, the lateral stiffness of the right column is $K=3 E I / h^{3}$, whereas that of the left column is 27 times greater. Hence, almost the whole horizontal force will be carried out by the left column (Fig. 16(b)), i.e., $F_{h 1} \cong \alpha M g$ and $F_{h 1} / F_{v 1}=2 \alpha=0.8$. Though ignoring the possibility of a short column failure for the left column, such a ratio between horizontal and vertical forces, certainly greater than the concreteto-concrete friction coefficient, indicates that the falling down of the beam from the column is to be expected. In the pushover curve of Fig. 2.4 reported by Casotto et al. (2015), the collapse due to connection failure is reached before the attainment of the flexural strength in the columns.

\section{Conclusions}

The results obtained from the analysis of damage data concerning 1421 precast RC industrial buildings hit by the 2012 Emilia seismic sequence are presented in the paper. About 96\% (1358 buildings) of the buildings examined are located in the struck region at epicentral distances not larger than $30 \mathrm{~km}$ and represent about $30 \%$ of the total stock of industrial buildings in the area. The strong motion data used in the study were obtained from the shakemaps of the two mainshocks that occurred on May $20^{\text {th }}$ and $29^{\text {th }}$, with $\mathrm{M}_{\mathrm{L}}=5.9$ and 5.8, respectively. In particular, for each building, three parameters were considered to establish the earthquake intensity, i.e., distance from the nearest epicentre, PSA at $1 \mathrm{~s}$ associated with the nearest epicentre, and maximum experienced PGA.

A six level damage scale, substantially corresponding to those given by EMS-98, was defined. The first level (D0) corresponds to undamaged buildings, whereas damage levels D1 to D5 refer to increasing levels of damage, from slight damages on non-structural elements up to partial or full building collapse. Then, on the basis of some correlations observed, the damage data were grouped into the three classes D0, D1+D2, and D3+D4+D5.

It was found that approximately $90 \%$ of the buildings of damage class D3+D4+D5 included in the study are located within $16 \mathrm{~km}$ from the epicentre and experienced a PSA larger than $0.12 \mathrm{~g}$. For $10 \%$ of the severely damaged to collapsed buildings, the PSA was larger than 0.29 g. Finally, a quadratic relationship was shown to fit accurately the cumulative frequency of undamaged buildings versus distance from the nearest epicentre, indicating that these buildings are almost uniformly distributed over the struck region. Indeed, 44\% of the 801 undamaged buildings considered are located within $20 \mathrm{~km}$ from the epicentre, and this percentage is very well approximated by the area ratio $A_{1} / A_{2}=0.44$, with $A_{1}=\pi 20^{2}$, and $A_{2}=\pi 30^{2}$ being circular surfaces with radii $R_{\text {epi }}=20$ and $30 \mathrm{~km}$, respectively, centred on the epicentre. It is worth observing that approximately $20 \%$ of the buildings that experienced a PSA $\geq 0.20 \mathrm{~g}$ were nevertheless undamaged. The circumstance that also close to the epicentres a significant number of buildings resulted undamaged indicates that some precast building typologies present a relatively low seismic vulnerability.

The damage distributions in terms of the maximum experienced PGA are characterized by a sudden increase in the number of damaged buildings for $P G A \geq 0.28 \mathrm{~g}$. This slope change is a consequence of the non-uniform distribution of the buildings included into the database and of the 
spatial distribution of the PGA.

Since very heavy damages and collapses were observed in a significant number of buildings up to about $15 \mathrm{~km}$ from the epicentres, and moderate damages affected buildings located up to 25-30 $\mathrm{km}$ from the epicentres (Fig. 13), future developments of the present investigation will be dedicated to a deeper analysis of the most common typologies of precast buildings, in order to put in evidence all possible sources of seismic vulnerability.

\section{Acknowledgments}

The present investigation was developed within the activities of the (Italian) University Network of Seismic Engineering Laboratories-ReLUIS in the research program funded by the (Italian) National Civil Protection- Progetto Esecutivo 2016 - Research Line "Reinforced Concrete Structures", WP2. The damage data were made available by the Emilia-Romagna region.

\section{References}

Baggio, C., Bernardini, A., Colozza, R., Corazza, L., Della Bella, M., Di Pasquale, G., Dolce, M., Goretti, A., Martinelli, A., Orsini, G., Papa, F. and Zuccaro, G. (2007), Field Survey for Post-Earthquake Damage and Safety Assessment and Short Term Countermeasures (AeDES) (Pinto, A.V., and Taucer, F., Eds.), EUR 22868 EN, ISSN 1018-5593, Joint Research Centre, Institute for the Protection and Security of Citizen.

Belleri, A., Torquati, M., Riva, P. and Nascimbene, R. (2015), "Vulnerability assessment and retrofit solutions of precast industrial structures", Earthq. Struct., 8(3), 801-820.

Biondini, F., Dal Lago, B. and Toniolo G. (2013), "Role of wall panel connections on the seismic performance of precast structures", Bull. Earthq. Eng., 11(4), 1061-1081.

Bournas, D.A., Negro, P. and Taucer, F. (2014), "Performance of industrial buildings during the Emilia earthquakes in Northern Italy and recommendations for their strengthening", Bull. Earthq. Eng., 12(5), 2383-2404.

Braga, F., Gigliotti, R., Monti, G., Morelli, F., Nuti, C., Salvatore, W. and Vanzi, I. (2014), "Speedup of post earthquake community recovery: the case of precast industrial buildings after the Emilia 2012 earthquake", Bull. Earthq. Eng., 12(5), 2405-2418.

Braga, F., Gigliotti, R., Monti, G., Morelli, F., Nuti, C., Salvatore, W. and Vanzi, I. (2015), "Post-seismic assessment of existing constructions: evaluation of the shakemaps for identifying exclusion zones in Emilia", Earthq. Struct., 8(1), 37-56.

Casotto, C., Silva, V., Crowley, H., Nascimbene, R. and Pinho R. (2015), "Seismic fragility of Italian RC precast industrial structures", Eng. Struct., 94, 122-136.

CEN (2004), European Committee for Standardization, Eurocode 2: Design of concrete structures, Part 1-1: General rules and rules for buildings, EN1992-1-1:2004, Brussels.

China Earthquake Field Investigation Report (2008), Sichuan, China M8 Earthquake, Global Risk Miyamoto, May.

Cultrera, G., Faenza, L., Meletti, C., D’Amico, V., Michelini, A. and Amato, A. (2014), "Shakemaps uncertainties and their effects in the post-seismic actions for the 2012 Emilia (Italy) earthquakes", Bull. Earthq. Eng., 12(5), 2147-2164.

Dolce, M. and Di Bucci, D. (2014), "National Civil Protection organization and technical activities in the 2012 Emilia earthquakes (Italy)", Bull. Earthq. Eng., 12(5), 2231-2253.

Emilia-Romagna Regional Decree No. 57/2012 (2012), http://www.regione.emilia-romagna.it/terremoto/gliatti-per-la-ricostruzione?b_start:int $=0$. 
Emilia-Romagna Regional Decree No. 91/2013 (2013), http://www.regione.emilia-romagna.it/terremoto/gliatti-per-la-ricostruzione/2013/ordinanza-n-91-del-29-luglio-2013/view.

EMS-98 (1998), European Macroseismic Scale, Cahiers du Centre Européen de Géodynamique et de Séismologie (Grünthal, G., Ed.), 15, Luxemburg.

FEMA 356 (2000), Federal Emergency Management Agency, Prestandard and Commentary for the Seismic Rehabilitation of Buildings, Washington, D.C.

Hadjian, A.H. (1993), "The Spitak, Armenia earthquake of 7 December 1988 - why so much destruction", Soil Dyn. Earthq. Eng., 12(1), 1-24.

INGV (2012), Italian National Institute of Geophysics and Volcanology. ShakeMap Home Page, http://shakemap.rm.ingv.it/shake/index.html.

Italian Building Code (2008), D.M. 14/01/2008, Rome.

Kafle, B., Lam, N.T.K., Lumantarna, E., Gad, E.F. and Wilson, J.L. (2015), "Overturning of precast RC columns in conditions of moderate ground shaking”, Earthq. Struct., 8(1), 1-18.

Korkmaz, K. and Karahan, A. (2011), "Investigation of seismic behavior and infill wall effects for prefabricated industrial buildings in Turkey", J. Perform. Constr. Facil., 25(3), 158-171.

Legislative Decree No. 74/2012 (2012), Italian Parliament, http://www.cgm3esse.com/normativa/terremotoemilia/testi-integrali.

Liberatore, L., Sorrentino, L., Liberatore, D. and Decanini, L.D. (2013), "Failure of industrial structures induced by the Emilia (Italy) 2012 earthquakes", Eng. Fail. Anal., 34, 629-647.

Marshall, J.D. and Gould, N.C. (2012), "The performance of low-rise industrial facilities in the 2010 Haiti and 2011 Christchurch, New Zealand, earthquakes", Proceedings of the $15^{\text {th }}$ World Conference on Earthquake Engineering, Lisbon, Portugal.

Michelini, A., Faenza, L., Lauciani, V. and Malagnini, L. (2008), "ShakeMap implementation in Italy", Seismol. Res. Lett., 79(5), 689-698.

Miyamoto, H.K., Gilani, A.S. and Wada, A. (2008), "Reconnaissance report of the 2008 Sichuan earthquake, damage survey of buildings and retrofit options", Proceedings of the $14^{\text {th }}$ World Conference on Earthquake Engineering, Beijing, China.

Ozden, S., Akpinar, E., Erdogan, H. and Atalay, H.M. (2014), "Performance of precast concrete structures in October 2011 Van earthquake, Turkey”, Magaz. Concrete Res., 66(11), 543-552.

Saatcioglu, M., Mitchell, D., Tinawi, R., Gardner, N.J., Gillies, A.G., Ghobarah, A., Anderson, D.L. and Lau, D. (2001), "The August 17, 1999, Kocaeli (Turkey) earthquake - damage to structures", Can. J. Civ. Eng., 28(4), 715-737.

Savoia, M., Mazzotti, C., Buratti, N., Ferracuti, B., Bovo, M., Ligabue, V. and Vincenzi, L. (2012), "Damages and collapses in industrial precast buildings after the Emilia earthquake", Ingegneria Sismica: Int. J. Earthq. Eng., 29(2-3), 120-131.

Sezen, H. and Whittaker, A.S. (2006), "Seismic performance of industrial facilities affected by the 1999 Turkey earthquake", J. Perform. Constr. Facil., 20(1), 28-36.

Tassios, T. and Vintzēleou, E. (1987), "Concrete-to-concrete friction”, J. Struct. Eng., 113(4), 832-849.

Toniolo, G. and Colombo, A. (2012), "Precast concrete structures: The lessons learned from the L'Aquila earthquake", Struct0 Concrete, 13(2), 73-83.

Wald, D.J., Worden, C.B., Quitoriano, V. and Pankow, K.L. (2006), ShakeMap ${ }^{\circledR}$ Manual, Technical Manual, User's Guide, and Software Guide, http://pubs.usgs.gov/tm/2005/12A01/pdf/508TM12-A1.pdf.

Yanev, P. (1989), "Performance of industrial facilities", Earthq. Spectra, 5(3), 101-113.

Yüksel, E. and Sürmeli, M. (2010), "Failure analysis of one-story precast structures for near-fault and farfault strong ground motions", Bull. Earthq. Eng., 8(4), 937-953. 